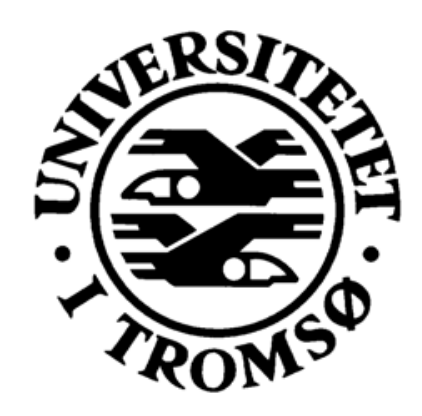

\title{
RATIONAL BENEVOLENCE IN SMALL COMMITTEES
}

Derek J. Clark and Christian Riis

Working Paper Series in Economics and Management

No. 10/06, September 2006

Department of Economics and Management

Norwegian College of Fishery Science

University of Tromsø

Norway 
Preliminary. Please do not quote. Version 26.09.2006

\section{RATIONAL BENEVOLENCE IN SMALL COMMITTEES}

by

Derek J. Clark ${ }^{1}$

and

Christian Riis ${ }^{2}$

September 2006

1. Department of Economics and Management, NFH, University of Tromsø, N-9037

Tromsø, Norway. Derek.Clark@,nfh.uit.no

2. Department of Economics, Norwegian School of Management BI, Nydalsveien 37, N-0442 Oslo, Norway. Christian.Riis@bi.no

Acknowledgement: We would like to thank participants at the WZB workshop "Advances in Auction Theory" for helpful discussions. All errors are our own. 


\begin{abstract}
We consider a pie-splitting game involving three committee members. In response to the large literature on sequential procedures in this type of game, we propose an institution that is inspired by auction theory. The (sealed) bids of the players are proposals for a distribution of the pie and are given simultaneously. If any of the bids is preferred to all others in a pairwise comparison (i.e. a Condorcet winner exists) then this proposal is implemented. If such a bid does not exist then an equal split of the pie is assumed. An equilibrium of this game is for each player to suggest that one of the opponents should receive the lion's share of the pie, even though each player cares only about his own share. We call this phenomenon "rational benevolence". Although the end that is desired by the players is purely egoistic, the means of achieving it may be perceived as benevolent. Several applications of the game are suggested.
\end{abstract}

Keywords: Committees, auctions.

JEL Classification: D7, D44. 


\section{Introduction}

There is no escape from the fact that agreements reached by committees and legislatures pervade our economic life; it should then not be surprising that economists and political scientists have, for many years, attempted to uncover a theory of how such decisions are made. Several strands of literature intertwine in this vast field, combining the mechanisms of collective choice with the institutions - such as majority voting - from new political economy. ${ }^{1}$ The path toward a theory of committee decision-making has been littered with disappointment. Arrow's (1951) infamous Impossibility Theorem showed at an early stage that a democratic collective choice mechanism will generally not be efficient. May's (1952) formalisation of majority voting - an often inherent feature of committee decision making - could not provide a way past Arrow's theorem, as it is now well known that this institution is prone to voting cycles, or can otherwise be manipulated. ${ }^{2}$

The set of rules governing the manner in which a committee or legislature reaches its decision is obviously of crucial importance for predicting the outcome. Again, the process of finding a set of rules that will lead to a decisive, efficient outcome has been problematic. To narrow the focus, let us concentrate on a simple pie-splitting (or divide-the-dollar) example in a committee or legislature that obeys the principle of pure majority rule, i.e. each member has one vote, and votes sincerely for the proposal yielding most personal utility. There are basically two ways in which proposals for the division of the pie can be pitched against each other. With an open agenda, proposals are voted on in pairs in a sequential fashion, where the winning proposal from a round of voting faces a subsequent one. Such a process often leads to cycling, and this does little to limit the range of possible outcomes at which the committee may arrive. Indeed, a famous result by McKelvey (1976) demonstrates that, under certain conditions ${ }^{3}$ a sequence of pairwise votes can lead to any outcome in the Pareto set - for the pie-splitting example this means that all divisions may be reached. The solution to this problem often involves invoking some form of closed agenda that specifies an endpoint for the process of proposal and counterproposal. However, the

\footnotetext{
${ }^{1}$ Inman (1987) gives a survey of some of the early literature here.

${ }^{2}$ On the former, the classic reference is Condorcet (1785), and on the latter, see Gibbard (1973) and Satterthwaite (1975).
} 
committee members may then find it profitable to attempt to manipulate the agenda in order to gain an advantage, further affecting the efficiency of the decision mechanism. Generally, Shepsle (1979) has suggested specifying the institution that governs the decisions of a group of representatives, and analysing how varying the institution affects the equilibrium outcome.

Myerson (1995) suggests that it may be fruitful to combine the insights from economic theory in analysing the functioning of political institutions (such as legislatures or committees). In this paper, we suggest a set of rules by which a committee (or similar group of representatives) may reach decisions, that is inspired by the economic analysis of auctions. It is well known that an open auction - for example an English auction - is often used in situations where the bidding can be expected to reveal information that is relevant for the actions of the participants. On the other hand, if there is a possibility that participants may attempt to strategically manipulate their actions then a closed (sealed bid) auction can be advantageous. ${ }^{4}$ There is an obvious analogy here to the open/closed agenda discussion above.

Klemperer (2003) highlights three core concerns in auction design: attracting entry, avoiding collusion and robustness to political pressure. Bearing this in mind he goes a long way to advocating the use of sealed-bid auctions. ${ }^{5}$ In our model entry is not an issue as the number of committee members is fixed, but collusion and political pressure are often problems in the functioning of especially small committees.

The institution that we specify is based upon a sealed bid auction in the following way. A three-member committee (or legislature) has to divide a pie of fixed size among its members; each member is purely self-interested and wishes to secure as much of the pie as possible for himself. Each member simultaneously proposes a distribution of the pie in the form of a sealed bid. ${ }^{6}$ The bids are then made known and if a Condorcet winner exists then this distribution is implemented. If no such proposal exists, then some pre-specified status quo distribution is effected. In analogy

\footnotetext{
${ }^{3}$ Specifically, with preferences from the Euclidian metric.

${ }^{4}$ For a comprehensive survey of modern auction literature, see Klemperer (1999).

5 Although he also stresses that in auction design "one size does not fit all".

${ }^{6}$ Lockwood (2002) also allows representatives to make proposals simultaneously, but these proposals are then randomly put into an order specifying the sequence in which they appear in the agenda.
} 
to the auction literature, we specify a fixed and credible rule for choosing among the bids.

The equilibrium that we derive from this game exhibits a type of manipulative behaviour that at first glance may appear somewhat surprising. In equilibrium it is rational for each member to offer one of the other members the lion's share of the pie, a phenomenon that we have chosen to call "rational benevolence". 7 The result is presented in the next section, and is discussed in Section 3.

\section{Rational benevolence}

The basic structure of the model is as follows. Three risk-neutral committee members, denoted by the set $M=\{A, B, C\}$ must divide a pie of size 1 among themselves by mutual consent. The payoff to a player is simply the share of the pie that he receives. The game is played once. Each player $j \in M$ submits a written proposal (sealed bid) simultaneously, specifying how the pie should be divided. Denote the proposal from player $j \in M$ by $\left(x_{A}^{j}, x_{B}^{j}, x_{C}^{j}\right)$, where $x_{A}^{j}+x_{B}{ }^{j}+x_{C}{ }^{j}=1$ (i.e. the whole pie is distributed). We introduce a further technical restriction on the proposals, namely that $2 / 3 \geq x_{i}^{j}$ for all $i, j \in M$. This restriction is needed to tie down the equilibrium and will be further commented upon below. We can view this as similar to the reserve price in an auction that limits the lowest/highest amount that can be suggested by the players.

Importantly, a proposal cannot be amended once it has been submitted. The bids are then opened, and the Condorcet winner is implemented if it exists. We rule out indifference in the pairwise comparison by assuming that bids are delivered with a small element of noise so that the probability of assigning the same share to any player is zero. ${ }^{8}$ If no Condorcet winner exists then a pre-specified division of the pie is used in which each player receives an equal share.

\footnotetext{
${ }^{7}$ Sidgewick (1877) introduced the Principle of Rational Benevolence into the philosophical literature. This notion is quite distinct from our concept and is further discussed in Section 3.

${ }^{8}$ As the noise component approaches zero one would need to specify a rule to break ties.
} 
Consider Figure 1 that depicts an equilateral triangle with altitudes equal to 1, representing the size of the pie. Side $i=A, B, C$ of the triangle represents a "baseline" for player $i$ from which this player's share is measured. A division of the pie can then be depicted by a point in the triangle; the further away this point is from player $i$ 's baseline, the larger share that will be allocated to that player. The division $(1 / 3,1 / 3$, $1 / 3$ ) is at the intersection of the three altitudes of the triangle.

In Figure 1, imagine that point $Z$ is the bid by one of the players; in a pairwise comparison, this point will beat proposals that are in the shaded areas, but will lose to divisions in the white areas. Compare $Z$ with $Y$ for example: $Z$ gives more to player $B$ and $C$ than $Y$, but less to $A$. In a pairwise comparison, $Z$ is preferred to $Y$.

To avoid technical details of minor interest, we focus on the symmetric equilibrium of the model. The unique symmetric equilibrium of the game is given in the following Proposition.

\section{Proposition}

The following mixed strategies constitute the unique symmetric equilibrium of the game: a) player A suggests division $(1 / 3,2 / 3,0)$ with probability 0.5 , and division $(1 / 3,0,2 / 3)$ with probability $0.5 ;$ b) player $B$ suggests division $(2 / 3,1 / 3,0)$ with probability 0.5 , and division $(0,1 / 3,2 / 3)$ with probability $0.5 ; c)$ player $C$ suggests division $(2 / 3,0,1 / 3)$ with probability 0.5 , and division $(0,2 / 3,1 / 3)$ with probability 0.5 .

In equilibrium, each player receives an expected share (payoff) of 1/3.

\section{Proof}

See appendix

\section{Discussion}

The behaviour that we see as a feature of the Proposition is what we call "rational benevolence", and has not featured in the relevant literature before as far as we are 
aware. A rational strategy to follow in this game is to offer the lion's share of the spoils to another actor, whilst the third player is given nothing. This equilibrium strategy is similar to buying an option with a full upside, and no downside. To explain the logic here, let us concentrate on the actions of player $A$, supposing that he proposes that $A$ be given $1 / 3$, and $B 2 / 3$. This is illustrated in Figure 2, where it is clear that this defeats all proposals giving $A$ less than 1/3. By making this offer to $B$, A secures his support for this proposal, and this guarantees $A$ no less than 1/3 (no downside); at the same time, threatening $C$ with nothing means that $C$ has an incentive to offer $A$ more than $1 / 3$, as this ensures $A$ 's vote (full upside).

Whilst it looks as if the proposals made in equilibrium reflect a caring for the other committee members, they are the outcome of a perfectly rational and egotistical strategy in this game. Quite apart from this is the principle of Rational Benevolence introduced into the philosophy literature by Sidgewick $(1877 ; 31)$ : “...the principle of Rational Benevolence, that sets before each man the good of all others as an object of pursuit no less worthy than his own". This of course parallels the original definition of altruism attributed to Comte (1851-54;400): "The chief problem of human life [is] the subordination of egoism to altruism". According to Korsgaard et. al (1996) one of the challenges of altruism is to show that "the points of view from which these different interests arise are congruent, that meeting the claims made from one point of view will not necessarily mean violating those that arise from another" (Korsgaard et al, 1996; 60-61). The problem of altruism has recently been addressed by Graham (2002) who focuses on preferences with regards to the ends that can be achieved. The altruistic component of the behaviour that we have identified focuses rather on the means by which these can be achieved. In our notion of rational benevolence, agents are inherently self-interested, but their observed behaviour is reminiscent of actions that would usually be assumed to originate from an altruistic set of preferences. This may also be regarded as a counterexample to Sen (1994) who argues that making agents' payoffs a function of their own outcome "has some difficulty in accommodating "social" behaviour such as ..... not grabbing the uniquely largest slice of cake" (Sen, 1994;385).

Our model has been inspired by auction theory so it is natural to look for a parallel result to ours in this literature. Our equilibrium outcome resembles that of McAfee 
and McMillan (1992) that a weak bidding ring (without cash payments between members) cannot do better than to randomize the right to bid between members and let one of them win at the reserve price. In the committee model the identity of the winner (i.e. the player that gets $2 / 3$ ) is random, but the amount achieved is always at the "reserve price". Within political economics, one may view equilibrium behaviour in this game as implicit logrolling in which proposals are "packaged" in order to make them palatable to the majority of the voters. ${ }^{9}$ Here the packaging involves an apparent benevolence to other members, not unlike the phenomenon of "bureaucratic deception" discussed by Tullock et al. (2000; 63).

We should emphasise again the fact that our results rest upon the assumption that no member can propose a share of more then $2 / 3$ of the pie to himself or any other member. This restriction seems necessary to guarantee the existence of equilibrium. Consider what would happen if this restriction were relaxed, so that it is possible to allocate at most $2 / 3+\varepsilon$ to one player. Suppose that B and C retain the equilibrium strategy from Proposition 1; then A's best response would be to randomize between the other players, giving one $2 / 3+\varepsilon$, and reducing his own share correspondingly. This strategy eliminates one of the outcomes in which player A gets zero with positive probability in the original equilibrium, and is hence better than the original equilibrium strategy. This cannot be an equilibrium situation, however, since the best response of $\mathrm{B}$ and $\mathrm{C}$ would be to reduce their shares in a similar manner. As the amount that can maximally be given to a single player is raised further, the best response is to keep reducing one's own share. As the bids approach the corner points in the triangle, however, a player can increase his share by proposing $1 / 3+\varepsilon$ to himself and $1 / 3-\varepsilon / 2$ to each opponent. The best reply to this would then be to give oneself $2 / 3$ and one of the other players $1 / 3$. But then the best response to this would be for the other players to reduce their own shares again and give most of the pies to one of the other players. So we have a cyclical situation (to which we - as yet - have found no end).

Finally, we note that the model permits several interpretations and applications. The pie to be divided can be thought of as an income or a cost; in the model presented

\footnotetext{
${ }^{9}$ Tullock et al. $(2000 ; 33)$ document that this strategy was used by President Eisenhower during his
} 
above, the pie represents income to the participants, but one could easily redefine the model so that the committee members are assigning cost shares among themselves. The three members could be states that must agree on tax shares to be paid to a federal government. Or the members could be partners in a Research Joint Venture that must divide project costs. Alternatively they could represent the Triple Helix of industry-government-university relations bargaining over cost shares in a joint project. ${ }^{10}$ In these "cost shares" applications, a rational strategy in the symmetric equilibrium would be for each actor to offer to pay the most (realising that in equilibrium this ensures an expected share of one third). 


\section{References}

Arrow, K. (1951): Social Choice and Individual Values, John Wiley, New York.

Comte A. (1851-54): Systeme de Politique Positive, Lenzer (printed in 1983).

Condorcet, M. de (1785): Essai sur l'application de l'analyse à la probabilité des decisions rendues à la plualité des voix, L'Impremerie Royale, Paris.

Etzkowitz, H. and L. Leydesdorff (1995), The Triple Helix - University-IndustryGovernment Relations: A laboratory for knowledge based economic development, EASST Review, 14, 14-19.

Gibbard, A. (1973): Manipulation of voting schemes: A general result, Econometrica, 41, 587-601.

Graham, K. (2002): Altruism, self-interest and the indistinctness of persons, Critical Review of International Social and Political Philosophy, 5(4), 49-67. Inman, R.P. (1987): Markets, government and the 'new' political economy, in A.J. Auerbach and M. Feldstein (eds.) Handbook of Public Economics, vol. 2, North Holland, Amsterdam.

Klemperer, P. (1999): Auction theory: A guide to the literature, Journal of Economic Surveys, 13 (3), 227-286.

Klemperer, P. (2003): Using and abusing economic theory, Journal of the European Economic Association, 1 (2-3), 272-300.

Korsgaard, C., G.A. Cohen, R. Geuss, T. Nagel and B. Williams (1996): The Sources of Normativity, Cambridge, Cambridge University Press.

Lockwood, B. (2002): Distributive Politics and the Benefits of Decentralisation, Review of Economic Studies, 69, 313-338.

May, K. (1952): A set of independent, necessary and sufficient conditions for simple majority decision, Econometrica, 20, 680-684.

McAfee, R.P and J. McMillan (1992): Bidding rings, American Economic Review, 82 (3), 579-599.

McKelvey, R.D. (1976): Intransitivities in multidimensional voting models and some implications for agenda control, Journal of Economic Theory, 12, 472-482.

Myerson, R. (1995): Analysis of democratic institutions: Structure conduct and performance, Journal of Economic Perspectives, 9 (1), 77-89. 
Satterthwaite, M.A. (1975): Strategy-proofness and Arrow's conditions: Existence and correspondence theorems for voting procedures and social welfare functions, Journal of Economic Theory, 10, 187-217.

Sen, A (1994): The formulation of rational choice, American Economic Review, 84(2) papers and Proceedings, 385-390.

Shepsle, K.A. (1979): Institutional arrangements and equilibrium in multidimensional voting models, American Journal of Political Science, 23, $27-59$. Sidgwick, H. (1877): Hedonism and ultimate good, Mind, 2(5), 27-38. Tullock, G., A. Seldon and G.L. Brady (2000): Government: Whose Obedient Servant?, Institute of Economic Affairs, London. 
Figure 1

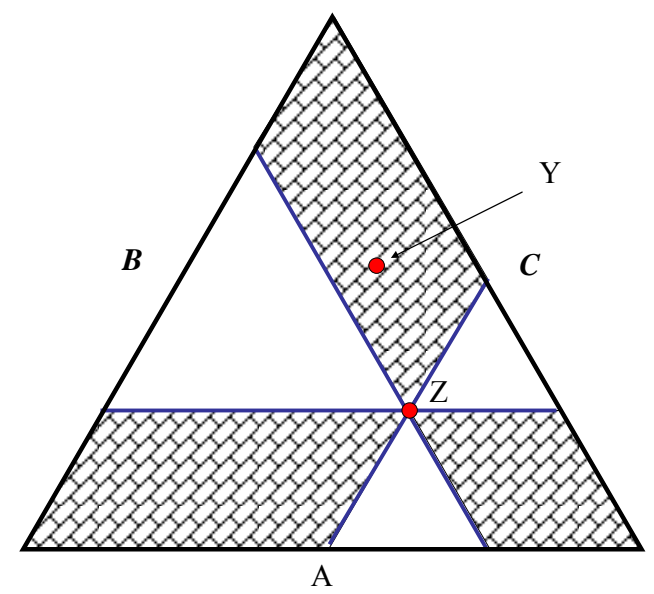


Figure 2

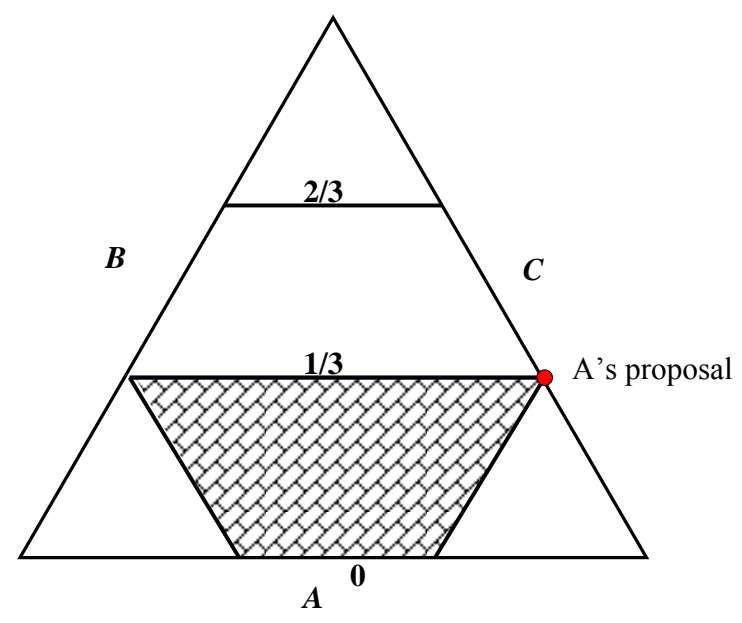




\section{Appendix}

Here we prove the Proposition.

We first show that the proposed equilibrium is a best reply, and then prove uniqueness. Assume B and C follow the proposed equilibrium strategy.

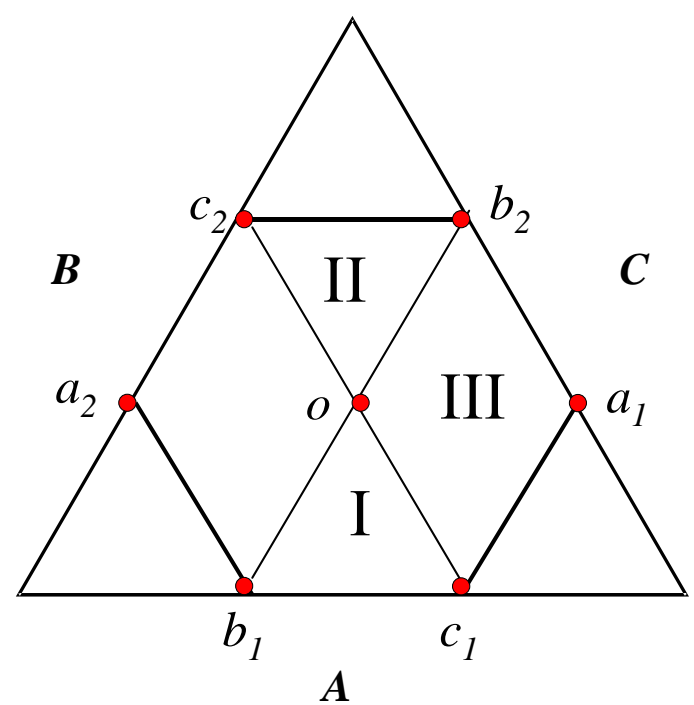

Figure A1

Consider Figure A1. We first show that there exists no $a \neq a_{1}, a_{2}$ which gives expected payoff larger than $1 / 3$. Observe first that any proposal $a$ in the interior of I, including segment $b_{1}-c_{1}$ strictly dominates $c_{2}, b_{2}$. Hence with zero probability A obtains strictly above $1 / 3$ and with strictly positive probability strictly below $1 / 3$. Secondly, any proposal in II, including the line segment $c_{2}-b_{2}$ is strictly dominated by $b_{1}, c 1$. Hence A obtains 0 in all cases, except in the event $c_{2}, b_{2}$ (which occurs with probability $1 / 4$ ) at which he obtains at most $2 / 3$. Third, any proposal in III is dominated by both $c_{1}$ and $c_{2}$ and the proposal dominates both $b_{1}$ and $b_{2}$. Hence A obtains either $1 / 3$ or C's proposal. However, conditioned on Cs proposal winning, the probability that A obtains 0 (that is if $\mathrm{C}$ proposes $c_{1}$ ) exceeds the probability of obtaining $2 / 3$ (if $\mathrm{C}$ proposes $c_{2}$ ) since $b_{1}$ strictly dominates $c_{2}$. Fourth, any proposal on the borderline between I and III (or II and III) provides A with a weighted average of what he obtains by bidding strictly inside I and strictly inside III (as with areas II and III). Fifth, regarding the line segment $c_{1}-a_{1}-b_{2}$ : Along $a_{1}-c_{1}$, any bid beats the inferior $c_{1}$ 
with positive probability (without reducing the probability of $2 / 3$ ), hence A's payoff increases as he moves towards $a_{1}$. Along $a_{1}-b_{2}$ observe that a proposal a strictly above $a_{1}$ cannot win, whereas a bid $a_{1}$ wins with positive probability (in situations where $c_{1}$ alternatively would have won).

Next we prove uniqueness. Consider figure A2.

Figure A2

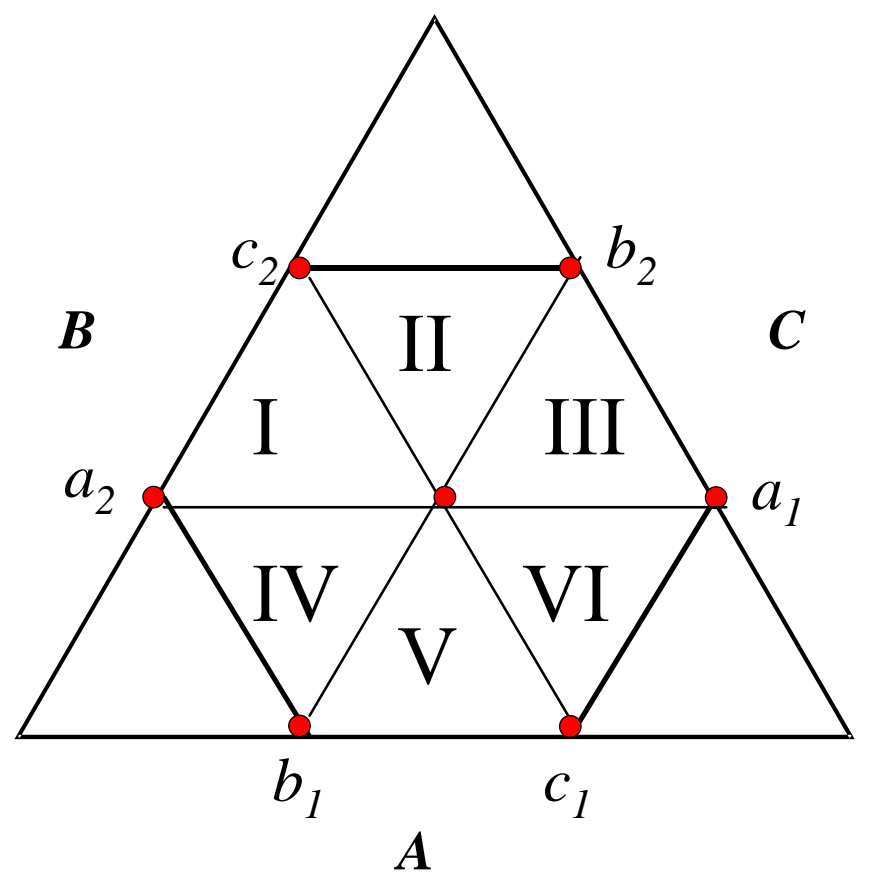

Assume B with certainty submits bids in area VI and A (by symmetry) with certainty in area II. Due to symmetry, $\min b^{C}=\min b^{A}$ where $\min b^{J}$ denotes the smallest share that $\mathrm{J}=\mathrm{A}, \mathrm{C}$ offers $\mathrm{B}$. If $\min b^{J}$ is not a masspoint, that proposal loses with certainty, hence $\mathrm{J}$ obtains at most $1 / 3$ and obtains less than $1 / 3$ with strictly positive probability. If $\min b^{J}$ is a mass point, $\mathrm{J}$ increases the probability of obtaining strictly more than $1 / 3$ (which occurs if his proposal wins and $\min b^{J}<1 / 3$ ), by offering B slightly more. 
Next $\min b^{J}=1 / 3$ (which is the pure strategy of splitting the pie evenly) is obviously not a symmetric equilibrium (it would be a best reply to redistribute in own favour, offering one of the opponents slightly more than $1 / 3$ ).

Hence in equilibrium, each player proposes to give at least one opponent strictly more than $1 / 3$, that is: with positive probability B submits bids in the areas I, II and/or III (as in IV and/or V due to symmetry). Consider any combination of bids from B and $\mathrm{C}$ that deviate from the equilibrium strategy. Then it follows that by bidding $a_{1}$, A's expected payoff strictly exceeds $1 / 3$. To see this, observe that any deviating bid that provides A with strictly less than $1 / 3$ is strictly dominated by $a_{1}-$ hence cannot win. Whereas the "twin-bid" (due to symmetry) which provides A with strictly more than $1 / 3$ wins with strictly positive probability. Hence any deviation yields A with a strictly positive upside and no downside. Since the game is zero-sum this contradicts an equilibrium. 